BMJ Open

Diabetes

Research

\& Care

\title{
Diabetes technologies for children and adolescents with type 1 diabetes are highly dependent on coverage and reimbursement: results from a worldwide survey
}

\author{
Tiago Jeronimo Dos Santos (D) , ${ }^{1}$ Chetankumar Dave, ${ }^{2}$ Sarah MacLeish, ${ }^{3}$ \\ Jamie R Wood ${ }^{3}$
}

To cite: Dos Santos TJ, Dave C, MacLeish S, et al. Diabetes technologies for children and adolescents with type 1 diabetes are highly dependent on coverage and reimbursement: results from a worldwide survey. BMJ Open Diab Res Care 2021;9:e002537. doi:10.1136/ bmjdrc-2021-002537

- Additional supplemental material is published online only. To view, please visit the journal online (http://dx.doi. org/10.1136/bmjdrc-2021002537).

Received 10 August 2021 Accepted 31 October 2021

Check for updates

\section{(C) Author(s) (or their} employer(s)) 2021. Re-use permitted under CC BY-NC. No commercial re-use. See rights and permissions. Published by BMJ.

For numbered affiliations see end of article.

Correspondence to Dr Tiago Jeronimo Dos Santos; tiagojer@gmail.com

\section{ABSTRACT}

Introduction To study healthcare professionals' (HCP) perceptions on decision making to start insulin pumps and continuous glucose monitoring (CGM) systems in pediatric type 1 diabetes.

Research design and methods An electronic survey supported by the International Society for Pediatric and Adolescent Diabetes (ISPAD) was disseminated through a weblink structured as follows: (1) HCP's sociodemographic and work profile; (2) perceptions about indications and contraindications for insulin pumps and (3) for CGM systems; and (4) decision making on six case scenarios. Results 247 responses from 49 countries were analyzed. Seventy per cent of respondents were members of ISPAD. Most of participants were women over 40 years old, who practice as pediatric endocrinologists for more than 10 years at university/academic centers and follow more than 500 people with type 1 diabetes. Although insulin pumps and CGMs are widely available and highly recommended among respondents, their uptake is influenced by access to healthcare coverage/insurance. Personal preference and cost of therapy were identified as the main reasons for turning down diabetes technologies. Parental educational level, language comprehension and income were the most relevant socioeconomic factors that would influence HCPs to recommend diabetes technologies, while gender, religious affiliation and race/ethnicity or citizenship were the least relevant.

Conclusions Responders seem to be markedly supportive of starting people on diabetes technologies. However, coverage/insurance for devices holds the biggest impact on the extent of their recommendations.

\section{INTRODUCTION}

Use of insulin pumps and continuous glucose monitoring (CGM) systems in the management of type 1 diabetes is gaining ground over conventional treatment with syringes, pens and glucometers. ${ }^{1-3}$ Although use of insulin pumps has been shown to lower $\mathrm{HbA}_{1 \mathrm{c}}$ levels in pediatric age when compared with multiple daily injections, few differences have been

\section{Significance of this study}

What is already known about this subject?

- Although the use of diabetes technologies seems to improve glycemic outcomes in the pediatric age group, their access is affected by countries' healthcare system coverage, clinicians' role in counseling, and individuals' and families' preferences.

What are the new findings?

- Most healthcare professionals (HCPs) are flexible in recommending diabetes technologies, especially when technologies are available from insurance/ coverage.

- Parental educational level, language comprehension and income were the most relevant socioeconomic factors that would influence HCPs to recommend diabetes technologies, while gender, religious affiliation, and race/ethnicity or citizenship were the least relevant.

- Personal preference and cost of therapy were identified as the main reasons for turning down diabetes technologies.

How might these results change the focus of research or clinical practice?

- The results of this survey pitch the idea that, for HCPs, universal coverage for diabetes technology may be as relevant as individuals' metabolic control when recommending diabetes technologies.

described in other glycemic outcomes. ${ }^{4-9}$ However, the use of integrated CGM systems has shown to improve time in range and decrease frequency and severity of hypoglycemia. ${ }^{10-12}$ In addition, people wearing these devices have reported increased flexibility and feeling of well-being. ${ }^{13}$

Despite these benefits, there are considerable differences between countries in healthcare system coverage of diabetes technologies, ${ }^{14-17}$ clinicians' role in counseling, 
and individuals' and families' preferences that prevent diabetes technologies from being used. ${ }^{1418} 19$ In addition, the hassle of wearing devices, dislike of alarms and inadequate counseling may also decrease their use. ${ }^{182021}$

There is a gap in the literature regarding the opinion of multinational healthcare professionals (HCPs) that are directly involved with recommendation of diabetes technologies. ${ }^{22}$ In addition, both socioeconomic background of people with diabetes and HCP's work profile may indirectly impact the willingness to recommend diabetes technologies. ${ }^{16}$ Therefore, with this survey, we aimed to comprehensively evaluate the reasons why providers do or do not recommend diabetes devices for children and adolescents with type 1 diabetes.

\section{METHODS}

We used an electronic survey powered by Survey Monkey Inc (San Mateo, California, USA) containing 33 questions in English language, and data were collected anonymously. The survey was disseminated through an open weblink for a calendar month to members of the International Society for Pediatric and Adolescent Diabetes (ISPAD) including past participants of annual meetings and training courses that approximately reach 2300 HCPs. Members were also encouraged to share the survey with colleagues that prevented us from being able to calculate a precise response rate. Responses were included if HCP confirmed their involvement in the decision or recommendation to start diabetes technology. If respondents completed the survey, $\$ 1$ was donated to Life for a Child Inc. The Standards for Reporting Qualitative Research guidelines were used in this study. ${ }^{23}$

The survey questions (online supplemental file 1) were divided into four topics: (1) baseline profile of HCPs; (2) HCPs' opinions about recommendation, use, and relevance of indications and contraindications for initiating insulin pumps); (3) HCP's opinions about recommendation and use of CGM; and (4) six case vignettes with variation of factors thought to impact decision to recommend diabetes technologies including individuals age, history of severe hypoglycemia, history of diabetic ketoacidosis, glycemic control, household composition, parental occupation, healthcare coverage, income, place of residence, parental literacy, immigration, religious affiliation, language comprehension, and social supports.

We did a post hoc subgroup analyses to compare responses between different subgroups, including: (1) age of HCP below or over 40 years old; (2) years of clinical practice under or over 10 years; (3) main practice setting - private, public/government or university/ academic hospital/outpatient clinic; (4) size of diabetes clinic - more or less than 200 patients being followed; (5) HCPs who consider themselves a racial/ethnic minority and those who do not; (6) provision of universal healthcare insurance/coverage for diabetes technologies; and (7) coverage/reimbursement from private insurance companies for diabetes technologies.
Categorical data are presented as proportions (\%), and comparisons between groups were based on a $\chi^{2}$ test or Fisher's exact test when appropriate. Qualitative data (content from the comments provided under 'Other, please specify') were analyzed using a coding technique, where similar answers are summarized by approximation into similar semantic content. ${ }^{24}$ The unit of analysis correspond to one single response, so one health center could have contributed more than one survey response. Statistical analyses were performed with Stata V.14.0 for Windows (College Station, Texas, USA). Statistical significance level was set at $\mathrm{p}<0.05$.

The survey was also approved by K.I.T. Group (Association \& Conference Management, Berlin, Germany) on behalf of the International Society for Pediatric and Adolescent Diabetes, and authors had the commitment to hold confidentially on collected data.

\section{RESULTS}

We received a total of 270 responses, with an average completion rate of $78 \%$ and a median time spent by participant of less than $10 \mathrm{~min}$. Nearly $91 \%(\mathrm{n}=247)$ of the survey responses were from HCPs involved in the decision or recommendation to start a person with diabetes on insulin pump and/or CGM and were included in the analysis. Seventy per cent of the respondents were members of ISPAD.

\section{Participant characteristics}

Table 1 summarizes participant characteristics. We highlight that approximately $45 \%$ of HCPs cannot count on their healthcare system to provide coverage for insulin pumps and/or CGM systems in their country/region of service, while $55 \%$ can fully or partially count on it. Approximately $46 \%$ of HCPs agreed that private insurance companies totally or partially cover/reimburse for insulin pumps and/or CGMs, while the other 54\% cannot count on their coverage.

\section{Viewpoints on insulin pumps}

Insulin pumps are available to more than 95\% of HCPs in their practice setting with at least $73 \%$ having more than one brand available. We saw significantly more uptake among patients whose HCPs had more years of practice, practiced in public/government or university/academic centers and followed more people with diabetes (table 2). Age and racial/ethnic minority did not show statistical differences.

There was significantly more use of, and agreement to start, insulin pump therapy in countries or regions that could rely on universal or partial healthcare insurance/ coverage for diabetes technologies and in those that could count on private insurance companies to cover/ reimburse diabetes technologies when compared with countries that could not (online supplemental file 2).

Reasons to turn down technology also differed depending on the coverage. In countries that could count on universal or partial healthcare insurance/ 
Table 1 Participant's characteristics

\begin{tabular}{lc|}
\hline Characteristics (no. of respondents) & Respondents (\%) \\
\hline $\begin{array}{l}\text { Age, years ( } \mathrm{n}=247) \\
\text { Under } 30\end{array}$ & $11(4.5)$ \\
\hline $30-40$ & $104(42.1)$ \\
\hline $41-50$ & $64(25.9)$ \\
\hline $51-60$ & $50(20.2)$ \\
\hline Over 60 & $18(7.3)$ \\
\hline Gender ( $\mathrm{n}=246)$ & \\
\hline Female & $158(64.2)$ \\
\hline Male & $88(35.8)$ \\
\hline Country $(\mathrm{n}=245)$ & \\
\hline India & $30(12.2)$ \\
\hline Brazil & $26(10.6)$ \\
\hline USA & $23(9.4)$ \\
\hline Canada & $20(8.2)$ \\
\hline Mexico & $14(5.7)$ \\
\hline Australia & $13(5.3)$ \\
\hline UK & $12(4.9)$ \\
\hline Chile & $11(4.5)$ \\
\hline Italy & $8(3.3)$ \\
\hline Portugal & $7(2.9)$ \\
\hline Belgium & $7(2.9)$ \\
\hline Others $\dagger$ & $74(30.2)$ \\
\hline
\end{tabular}

Consider themselves to be from minority racial/ethnic group $(n=245)$

Yes

$30(12.2)$

No

$215(87.8)$

Current clinical role $(n=245)$

Resident

$6(2.4)$

Primary care practitioner,

pediatrician, family doctor,or internal medicine doctor

Pediatric endocrinology fellow

$18(7.3)$

Pediatric endocrinologist/

$154(62.9)$

diabetologist

Adult endocrinology fellow

Adult endocrinologist/diabetologist

$24(9.8)$

Nurse practitioner/registered nurse

$24(9.8)$

Other (registered nutritionist,

$13(5.3)$

dietitian, nutritionist, diabetes

educator, mental health professional)

Years of practice $(n=246)$

Less than 3

$42(17.1)$

3-5

$37(15)$

5-10

More than 10

$121(49.2)$

Main practice setting $(n=245)$

\begin{tabular}{|c|c|}
\hline Characteristics (no. of respondents) & Respondents (\%) \\
\hline Private hospital/outpatient clinic & $56(22.9)$ \\
\hline $\begin{array}{l}\text { Public or government hospital/ } \\
\text { outpatient clinic }\end{array}$ & $73(29.8)$ \\
\hline $\begin{array}{l}\text { University or academic hospital/ } \\
\text { outpatient clinic }\end{array}$ & $104(42.5)$ \\
\hline Primary care center & $4(1.6)$ \\
\hline General practitioner office & $2(0.8)$ \\
\hline Other (diabetes association) & $6(2.5)$ \\
\hline \multicolumn{2}{|c|}{$\begin{array}{l}\text { Access to an endocrinologist/diabetologist as a consultant } \\
(n=247)\end{array}$} \\
\hline Yes & $56(22.7)$ \\
\hline No & $3(1.2)$ \\
\hline $\begin{array}{l}\text { She/he is an endocrinologist/ } \\
\text { diabetologist }\end{array}$ & $188(76.1)$ \\
\hline \multicolumn{2}{|c|}{ Number of patients with T1D followed $(n=247)$} \\
\hline Less than 100 & $71(29.1)$ \\
\hline $100-200$ & $42(16.9)$ \\
\hline $201-500$ & $59(23.8)$ \\
\hline More than 500 & $75(30.2)$ \\
\hline
\end{tabular}

Provision of universal healthcare insurance/coverage for the use of insulin pump and/or CGM systems in your country $(\mathrm{n}=247)$

$\begin{array}{lr}\text { Yes } & 65(26.3) \\ \text { No } & 112(45.3) \\ \text { Partially } & 70(28.3)\end{array}$

Coverage/reimbursement of private insurance companies for insulin pump and/or CGM systems in your country $(n=246)$

$\begin{array}{lc}\text { Yes } & 57(23.2) \\ \text { No } & 132(53.7) \\ \text { Partially } & 59(24)\end{array}$

Member of the International Society for Pediatric and Adolescent Diabetes $(n=247)$

$\begin{array}{lr}\text { Yes } & 173(70) \\ \text { No } & 74(30)\end{array}$

*Top 11 country.

†Countries with response: Argentina, Bangladesh, Bulgaria, Denmark, Ecuador, Egypt, Finland, Germany, Greece, Haiti, Indonesia, Ireland, Israel, Japan, Liberia, Luxembourg, Malaysia, Malta, Mauritius, Morocco, Myanmar, Netherlands, Norway, Pakistan, Paraguay, Peru, Poland, Republic of Korea, Romania, Saudi Arabia, Serbia, Slovenia, South Africa, Spain, Sweden, Thailand, Turkey and Uruguay.

CGM, continuous glucose monitoring; T1D, type 1 diabetes.

coverage, the main reason for declining diabetes technology was 'not wanting to wear something on the body', while in countries where diabetes technologies are not covered, the main reason was the difficulty to afford or maintain therapy (online supplemental file 2). Providers who were older than 40 years ( $58 \%$ vs $39 \%$, $\mathrm{p}=0.03$ ), with 
Table 2 Percentages of patients counseled by HCP that agreed or consented to start insulin pump therapy

\begin{tabular}{|c|c|c|c|c|c|}
\hline \multirow[b]{2}{*}{ No. of responses by HCP subgroups, (\%) } & \multicolumn{4}{|c|}{ Percentage of patients } & \multirow[t]{2}{*}{$P$ value } \\
\hline & $<25 \%$ & $25 \%-50 \%$ & $50 \%-75 \%$ & $>75 \%$ & \\
\hline Age & & & & & NS \\
\hline$\leq 40$ years old: 85 (44.7) & $20(23.5)$ & $21(24.7)$ & $21(24.7)$ & $23(27.1)$ & \\
\hline >40 years old: 105 (55.3) & $24(22.9)$ & $17(16.2)$ & $33(31.4)$ & $31(29.5)$ & \\
\hline Years of practice & & & & & 0.001 \\
\hline s10years: 97 (48.0) & $36(37.1)$ & $19(19.6)$ & $20(20.6)$ & $22(22.7)$ & \\
\hline >10years: $105(52.0)$ & $14(13.3)$ & $20(19.1)$ & $36(34.3)$ & $35(33.3)$ & \\
\hline Practice setting & & & & & 0.008 \\
\hline Private hospital: 48 (24.2) & $20(41.7)$ & $13(27.1)$ & 7 (14.6) & $8(16.7)$ & \\
\hline Public/governmental: 59 (29.8) & $14(23.7)$ & $9(15.2)$ & $16(27.1)$ & 20 (33.9) & \\
\hline University/academic: 91 (46.0) & 15 (16.5) & $17(18.7)$ & $30(33.0)$ & $29(31.9)$ & \\
\hline Clinic size & & & & & 0.020 \\
\hline$\leq 200$ patients with T1D: 93 (46.0) & $31(33.3)$ & $19(20.4)$ & $18(19.3)$ & $25(26.9)$ & \\
\hline >200 patients with T1D: 110 (54.0) & $19(17.3)$ & 20 (18.2) & $38(34.5)$ & $33(30.0)$ & \\
\hline Healthcare coverage & & & & & $<0.001$ \\
\hline Universal or partially: 84 (41.4) & $40(47.6)$ & $13(15.5)$ & $19(22.6)$ & $12(14.3)$ & \\
\hline No coverage: 119 (58.6) & $10(8.4)$ & $26(21.8)$ & $37(31.1)$ & $46(38.7)$ & \\
\hline Insurance reimbursement & & & & & $<0.001$ \\
\hline Yes, or partially: 96 (47.5) & $9(9.4)$ & $22(22.9)$ & $33(34.4)$ & $32(33.3)$ & \\
\hline No: 106 (52.5) & $41(38.7)$ & $17(16.0)$ & $22(20.7)$ & $26(24.5)$ & \\
\hline Racial/ethnic minority HCP & & & & & NS \\
\hline Yes: 21 (10.4) & $6(28.6)$ & $3(14.3)$ & $9(42.9)$ & $3(14.3)$ & \\
\hline No: 181 (89.6) & $44(24.3)$ & 36 (19.9) & $47(26.0)$ & $54(29.8)$ & \\
\hline
\end{tabular}

HCP, healthcare professionals; NS, non-significant; T1D, type 1 diabetes.

more years of practice $(64 \%$ vs $35 \%, \mathrm{p}<0.001)$ and with a greater number of people with diabetes followed $(61 \% \mathrm{vs}$ $38 \%, \mathrm{p}<0.001)$ were more likely to endorse their reason to turn down technology as 'Patient does not want to wear something on its body'.

More than $80 \%$ of HCPs agreed with the statement 'All patients, regardless of circumstance, should be offered insulin pump therapy', and nearly $90 \%$ disagreed with the statement 'No patient, regardless of circumstance, should be offered insulin pump therapy'. No differences were seen between subgroups.

In order of importance, HCPs considered 'history of severe hypoglycemia', 'requirement of small doses of insulin', 'suboptimal glycemic control despite good compliance' and 'patient age' as extremely relevant indications to start insulin pump. 'Patient or caregiver's preference' was considered fairly relevant for most HCPs. No statistical differences were seen between subgroups.

Overall, a 'history of infrequent blood glucose monitoring (less than three times per day) or no use of CGM' and 'infrequent follow-up' were considered the most relevant absolute contraindications to starting a person with diabetes on insulin pump, regardless of healthcare coverage/insurance reimbursement. However, HCPs that cannot count on coverage for insulin pump were more likely to endorse infrequent blood glucose monitoring as a relative contraindication for starting an insulin pump when compared with HCPs who could count on coverage (online supplemental file 2). Other reasons like 'age less than 3 years old' and 'one or more episodes of DKA' were not found to be contraindications, whereas most of HCPs found 'inadequate parental/caregiver supervision' as a relative contraindication.

Figure 1 shows that among socioeconomic factors assessed, 'parental educational level', 'family/patient first language being different from that of the diabetes team', 'parental affordability to maintain therapy or having it provided by insurance coverage', and 'family income' were mostly considered as relevant factors in the decision making to start insulin pump. Other socioeconomic factors such as 'gender', 'religious affiliation', 'race, ethnicity, or citizenship', 'place of residence (rural vs urban)', and 'family social networking (belonging to social support groups)' were mostly found to be totally irrelevant factors. No statistical differences were seen between subgroups.

\section{Viewpoints on CGM systems}

Almost 95\% of the respondents have CGM systems available in their practice; of which, at least $85 \%$ have access 
Place of residence: Rural versus urban

Race, ethnicity or citizenship

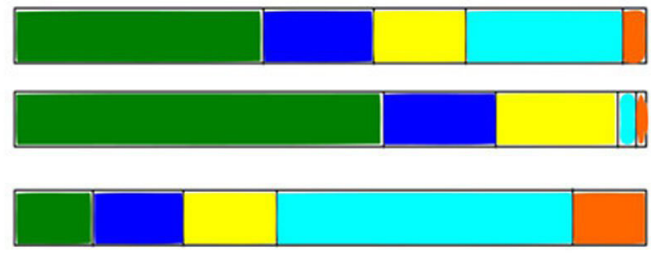

Family/patient speaks/comprehends different language than diabetes team

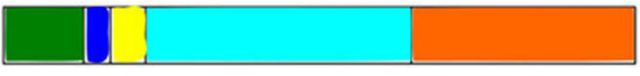

\section{Parental affordability to maintain the therapy or provision by insurance coverage}

Gender

Religious affiliation

Parental educational level

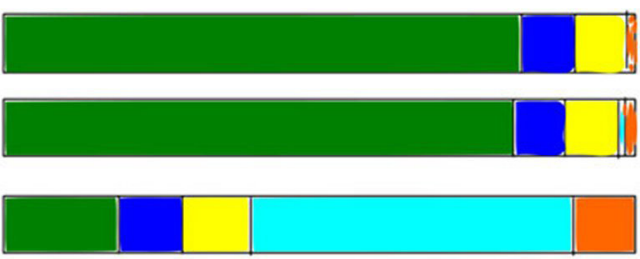

Family income

Family social networking: belonging to social support groups

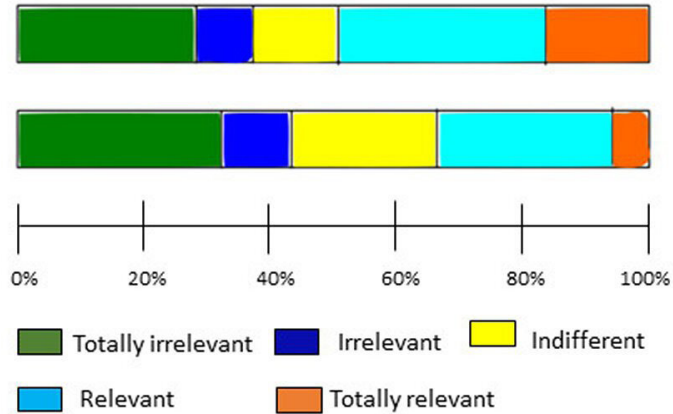

Figure 1 Relevance of socioeconomic factors when insulin pumps are prescribed or recommended.

to more than one brand. Although more than half of people with diabetes agreed to start CGM, only roughly one-third of them regularly wear it. Those people whose HCPs were under 40 years of age were found to have more access to CGM (57.6\% vs $35.4 \%, \mathrm{p}=0.019)$. A significantly higher percentage of people that use CGM have coverage for it compared with those who do not $(\mathrm{p}<0.01)$. In the same line, we saw a higher uptake of CGM in those who can count on insurance coverage for CGM when compared with those who do not $(p<0.01)$. The percentage of people that agreed/consented to use CGM after it was recommended was affected by coverage for CGM $(\mathrm{p}<0.01)$ and insurance reimbursement $(\mathrm{p}<0.01)$.

\section{Case scenarios}

One-year-old girl, during her partial remission phase, receiving $2.5 \mathrm{IU} /$ day of basal long-acting analog insulin, and doing corrections with rapid-acting analogues when needed, has faced two severe hypoglycemia episodes, one of them with seizures. She has a single mother, unemployed, and they live in a country where there is universal coverage for CSII and CGM.

Nearly $80 \%$ of the HCP respondents would recommend both insulin pump and CGM, and 18\% would only recommend CGM in this scenario (figure 2A). HCPs from university or academic hospitals were more likely to recommend both insulin pump and CGM than
HCPs from other settings, $90.3 \%$ and $73 \%$, respectively, $\mathrm{p}=0.012$.

One-year-old girl, during her partial remission phase, receiving $2.5 \mathrm{IU} /$ day of basal long-acting analog insulin, and doing corrections with rapid-acting analogues when needed, has faced two severe hypoglycemia episodes, one of them with seizures. She lives with her parents in a wealthy village fourhour away from nearest diabetes center, and family has full insurance coverage for CSII and CGM.

About $84 \%$ of the HCP respondents would recommend both insulin pump and CGM, and $12 \%$ would only recommend CGM in this scenario (figure 2B). HCPs from university or academic hospitals were more likely to recommend both insulin pump and CGM than HCPs from private or public/governmental setting (93\%, 76\% and $80 \%$, respectively, $\mathrm{p}=0.009$ ).

A 6-year-old girl has been suffering blood sugar fluctuations which include one episode of diabetic ketoacidosis last month. Her parents are facing a difficult economic situation because both are unemployed and do not have insurance coverage for diabetes suppliers. The young parents have not completed their secondary studies, and family lives in a deprived area of a big city.

Around $15 \%$ of the HCP respondents would recommend both insulin pump and CGM, and 39\% would only 
A

"I would recommend insulin pump for

this girl"

"I would recommend CGM for this girl"

"I would recommend both insulin pump and CGM for this girl"

"I would not recommend either of them"

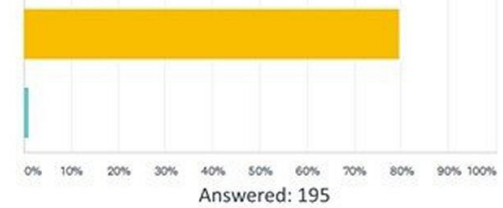

\section{C}

"I would recommend insulin pump for

this girl"

"I would recommend CGM for this girl"

"I would recommend both insulin pump and CGM for this girl"

"I would not recommend either of them"

\section{E}

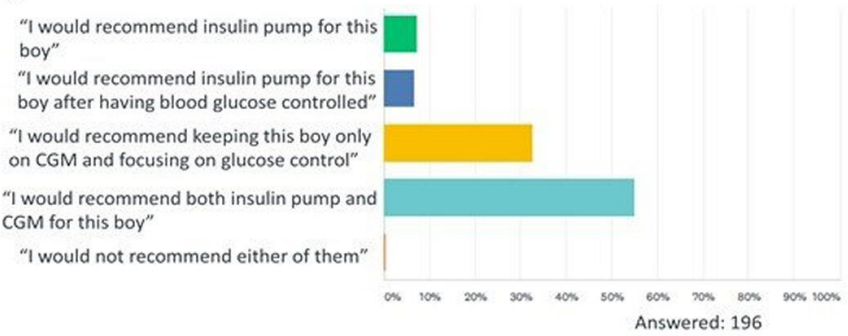

B

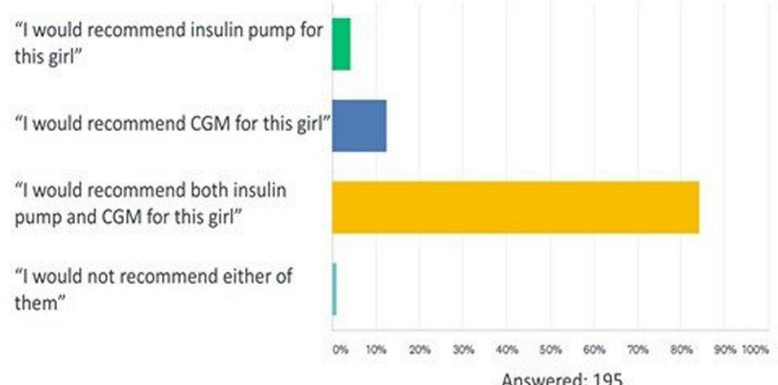

D "I would recommend insulin pump for this girl"

"I would recommend CGM for this girl"

"I would recommend both insulin pump and CGM for this girl"

"I would not recommend either of them"

\section{$\mathbf{F}$}

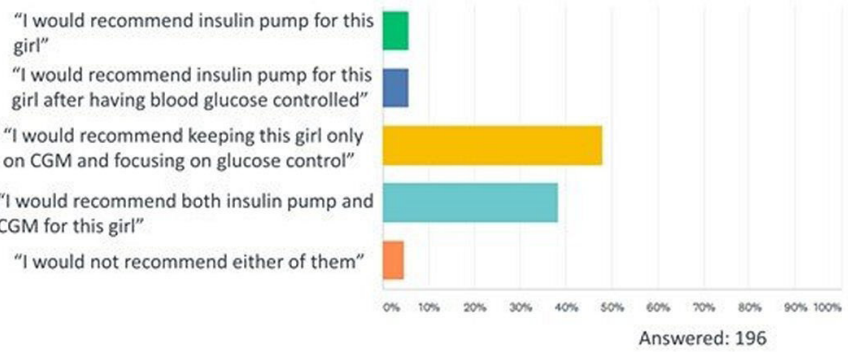

Figure 2 Global results on the six different case vignettes assessing factors thought to impact decision to recommend diabetes technologies for pediatric type one diabetes. (A) first case scenario; (B) second case scenario; (C) third case scenario; (D) fourth case scenario; (E) fifth case scenario; and (F) sixth case scenario. CGM, continuous glucose monitoring.

recommend CGM in this scenario; however, $45 \%$ of the respondents would not recommend insulin pump nor CGM (figure 2C). While 52\% of HCPs from university or academic hospital settings would recommend CGM, $33 \%$ and $24 \%$ of the HCPs from private and public/ government hospitals, respectively, would recommend it $(p=0.02)$. Moreover, $46 \%$ of the HCPs who follow more than 200 patients would recommend CGM, while $27 \%$ of the HCPs who follow less than 200 patients would recommend it $(\mathrm{p}=0.008)$.

A 6-year-old girl has been suffering blood sugar fluctuations which include one episode of diabetic ketoacidosis last month. The family recently moved to a new country where there is universal healthcare and coverage for CSII and CGM. The family belongs to a minority religion and has low language comprehension in their new country.

Close to $48 \%$ of HCPs would recommend both insulin pump and CGM, and $41 \%$ would recommend only CGM in this scenario (figure 2D). No significant differences were seen between subgroups.

An adolescent boy, from a racial/ethnic minority group, diagnosed eightyears ago, lives with his grandmother who works as a nurse and is his only guardian. Their health insurance recently approved him the provision of an intermittent CGM (Libre flash). He has suffered uncontrolled blood glucose, despite been on MDI with intensive basal-bolus requiring $1.8 \mathrm{IU} / \mathrm{kg} /$ day. Every year he participates in a regional diabetes camp.

Approximately 55\% of the respondents would recommend both insulin pump and CGM in this scenario, and $33 \%$ would recommend only CGM (figure 2E). Nearly $68 \%$ of the HCPs who follow more than 200 patients would recommend both therapies, while $47 \%$ of the HCP who follow less than 200 patients would recommend them $(\mathrm{p}=0.04)$.

A Caucasian adolescent girl, belonging to a major racial/ ethnic group, diagnosed eightyears ago, lives with her grandparents who are retired. Their health insurance recently approved her the provision of an intermittent CGM (Libre flash). She has been suffering uncontrolled blood glucose, despite been on MDI with intensive basalbolus requiring $1.8 \mathrm{IU} / \mathrm{kg} /$ day. In the village where they live, there are lacking of social support and counselling.

Approximately $38 \%$ of the respondents would recommend both insulin pump and CGM in this scenario, and $48 \%$ of the respondents would recommend only CGM (figure 2F). Nearly $48 \%$ of the HCPs who count on diabetes technology coverage would recommend both 
therapies, while $33 \%$ who cannot count on coverage would recommend them $(p=0.03)$.

$\mathrm{HCP}$ responses to vignettes $\mathrm{A}$ and $\mathrm{B}$ demonstrate that HCPs have similar recommendations about insulin pump and CGM for children and adolescents with diabetes with healthcare coverage/insurance despite family differences in household composition and employment, although HCPs from university or academic hospitals seem to be more likely to recommend both therapies. HCPs recommendations in vignettes $\mathrm{C}$ and $\mathrm{D}$ may have differed because of the absence of insurance coverage in addition to other difficult social circumstances in vignette C, unlike what was presented in vignette iv where universal healthcare and coverage were present even though the child was from a minority group and had low language comprehension. Although both adolescents in vignettes $\mathrm{E}$ and $\mathrm{F}$ had healthcare insurance/coverage, the girl in vignette $\mathrm{F}$ without social support and counseling was less likely to have an insulin pump recommended by HCPs, especially in those that cannot rely on healthcare coverage for diabetes technologies.

\section{DISCUSSION}

We performed an electronic, worldwide, survey with responses from $249 \mathrm{HCPs}$ from 49 different countries to assess their viewpoints on recommending insulin pumps and CGM systems for children and adolescents with type 1 diabetes. Although most HCPs were working at university/academic centers with a considerable number of people with type 1 diabetes, approximately $45 \%$ cannot count on their national/regional healthcare system to cover diabetes technologies, and 56\% cannot count on insurance companies' reimbursement to cover the cost of diabetes technologies. Even so, our findings suggest that most HCPs are very flexible in recommending insulin pumps and CGMs, but different impressions depended on age, years of practice, clinical setting, number of patients, and availability of coverage for diabetes technology.

Our main finding is significantly more adoption of insulin pumps and CGM systems in those having healthcare or insurance coverage for diabetes devices. Although 95\% of HCPs have insulin pumps and CGM systems available at their practice setting, the lack of coverage for them is an immediate explanation for the weak uptake. Countries with universal healthcare and wider availability of diabetes technologies, along with insurance-based countries with coverage for diabetes technologies are more likely to have a higher proportion of people with diabetes using technology, whereas most developing countries, despite holding universal healthcare, do not finance the newest diabetes delivery devices and make access to diabetes technology more limited. ${ }^{14152526}$ However, after cost and economic concerns, the most common reason to turn down technology has been pointed out to be wearrelated issues, in line with what was found in our survey. ${ }^{21}$

Three large international registries of type 1 diabetes in developed countries demonstrated that less than $50 \%$ of youth assessed were receiving pump therapy, and the rate of insulin pump usage was dependent on age group, ethnicity, and gender. ${ }^{25}$ In the same line, an international network of pediatric diabetes centers stated that coverage and reimbursement policies for diabetes technologies are very heterogeneous in Europe, which may cause inequality in diabetes management. ${ }^{27}{ }^{28}$ However, the uptake of diabetes technologies may be higher when insurance coverage is approved even when used in people with lower socioeconomic status. ${ }^{14} 29$

Our post hoc analysis evaluated a few variables found to be important in decision making about insulin pumps and CGM systems. HCPs with more years of experience who are working at centers with larger number of patients and larger multidisciplinary teams may provide different quality of care. ${ }^{27}$ In our study, this group of HCPs were more likely to extend flexibility to their patients to start on pumps or turndown this technology, especially when they can count on healthcare/insurance coverage for them. We believe that coverage for diabetes technologies could influence the access to these devices and HCP's personal impressions on recommending it, as innovative therapies may facilitate the motivation to improve outcomes. ${ }^{2}$ For instance, some HCPs were keener to recommend and prescribe them when family income was not an issue.

We assessed HCP's recommendation of insulin pump and CGM systems with two strategies. First, we asked providers to rate the relevance of various socioeconomic factors in their decision to recommend insulin pumps. Second, we used six case scenarios to explore the same socioeconomic factors. In the first strategy, HCP's viewpoints about the relevance of socioeconomic factors did not seem to vary by presence or absence of healthcare/ insurance coverage for diabetes devices. However, with the second strategy, we saw some different viewpoints, especially when diabetes technology coverage was absent. When the coverage for diabetes technology exists, younger age along with severe hypoglycemic episodes seemed to be a factor for greater adoption of pumps and CGMs. School-age children with similar social circumstances are more likely to be advised to start on pumps and CGMs if they are covered by healthcare system. For the adolescent group with similar suboptimal glycemic control and coverage for diabetes technologies, the lack of social support and counselling seemed to be associated with less recommendation for starting an insulin pump. Indeed, it is important to highlight that the six case vignettes were created by the authors, based on their expertise, and supported by the ISPAD, to assess main clinical conditions and different socioeconomic factors that might impact on recommendation of diabetes technologies. However, as the vignettes are not validated in the literature, the results should be read with cautious before being extrapolated into clinical decision making.

The results of our survey are in line with previous studies that showed that universal coverage for diabetes technology may be as relevant as individuals' metabolic control when HCPs recommend diabetes 
technologies. ${ }^{25} 3031$ Additionally, some modifiable socioeconomic factors, such as language comprehension, educational level and income would also influence HCPs to recommend technology. However, while unmodifiable socioeconomic factors such as gender, religious affiliation and race/citizenship seemed to be less important in their decision, background $\mathrm{HbA}_{1 c}$ level does not appear to influence the initiation of insulin pumps. ${ }^{30}$

Given the results of our study, guidelines and educational programs for starting insulin pumps and/or CGMs should address some of the perceived barriers to starting diabetes technologies including language comprehension, parental educational level, and social supports. Video interpretation services and educational material in different languages, for example, should be used during education for families who do not speak the same language as the diabetes team. Educational material should also be adapted so that parents of different educational levels can all be successful.

Our study has some limitations. First, individual responses of HCPs might not be representative of their whole country/region but represent an effort to acknowledge the viewpoints from members of an international medical society. Second, our survey was targeted to HCPs who were ISPAD members, comprising $70 \%$ of the respondents; however, the other $30 \%$ of respondents were mostly pediatric endocrinologists with more than 10 years of practice, who follow less than 100 people with diabetes at their clinic, working in a country/region that lacks coverage/reimbursement for insulin pump and CGM systems. We believe that the dissemination through an open weblink reduced a sampling bias, by surveying HCPs either belonging to ISPAD community or not, and balanced a response (acquiescence) bias that happens when respondents subconsciously or consciously express in less-than-truthful responses, most of them in agreement with the society view, since they belong to the same medical society. ${ }^{32} 33$

We conclude that most HCPs that participated in this survey are aware of the advantages of using diabetes technologies and are permissive to recommend them to benefit their patients. Although personal's clinical circumstances, language comprehension, educational level, and income affect the recommendation to initiate these technologies, the availability of insurance/coverage for diabetes technology seems to be the biggest factor when HCPs are deciding to recommend them. Therefore, it should be a policy priority to ensure coverage for diabetes technologies, especially in young age groups. Moreover, educational programs, resources, and strategies should be developed so that parental education level and language comprehension are no longer barriers to accessing diabetes technology.

\footnotetext{
Author affiliations

${ }^{1}$ Department of Preventive Medicine and Public Health, School of Medicine, Universidad Autónoma de Madrid, Madrid, Spain

${ }^{2}$ Center for Pediatric Endocrinology and Diabetes, Rajkot, India
}

${ }^{3}$ Department of Pediatric Endocrinology, UH Rainbow Babies and Children's Hospital, Case Western Reserve University, Cleveland, Ohio, USA

Acknowledgements We wish to express our gratitude to all respondents for their participation in the survey. Not only for their time spent, but also for their valuable input that made this research possible. We also would like to acknowledge the K.I.T. Group (Association \& Conference Management, Berlin, Germany) on behalf of the International Society for Pediatric and Adolescent Diabetes who approved, guided, and helped us to disseminate the survey throughout its membership.

Contributors All authors conceptualized the survey. TJDS, CD and JRW worked on methodology and formal analyses. TJDS and CD wrote the original manuscript. SM and JRW reviewed and edited. JRW is the scientific guarantor of this study. All the authors approved the last version of the manuscript.

Funding Small amount of the expenses to create and analyze data was provided from the awarded International Society for Pediatric and Adolescent Diabetes 'Allan Drash Clinical Fellowship' grant.

Competing interests None declared.

Patient consent for publication Not applicable.

Ethics approval The Research Ethics Committee from the Universidad Autónoma de Madrid confirmed that the project did not require ethics committee approval.

Provenance and peer review Not commissioned; externally peer reviewed.

Data availability statement All data relevant to the study are included in the article or uploaded as supplementary information.

Supplemental material This content has been supplied by the author(s). It has not been vetted by BMJ Publishing Group Limited (BMJ) and may not have been peer-reviewed. Any opinions or recommendations discussed are solely those of the author(s) and are not endorsed by BMJ. BMJ disclaims all liability and responsibility arising from any reliance placed on the content. Where the content includes any translated material, BMJ does not warrant the accuracy and reliability of the translations (including but not limited to local regulations, clinical guidelines, terminology, drug names and drug dosages), and is not responsible for any error and/or omissions arising from translation and adaptation or otherwise.

Open access This is an open access article distributed in accordance with the Creative Commons Attribution Non Commercial (CC BY-NC 4.0) license, which permits others to distribute, remix, adapt, build upon this work non-commercially, and license their derivative works on different terms, provided the original work is properly cited, appropriate credit is given, any changes made indicated, and the use is non-commercial. See: http://creativecommons.org/licenses/by-nc/4.0/.

ORCID iD

Tiago Jeronimo Dos Santos http://orcid.org/0000-0001-9682-0289

\section{REFERENCES}

1 Danne T, Nimri R, Battelino T, et al. International consensus on use of continuous glucose monitoring. Diabetes Care 2017:40:1631-40.

2 Tauschmann M, Hovorka R. Technology in the management of type 1 diabetes mellitus - current status and future prospects. Nat Rev Endocrinol 2018;14:464-75.

3 Sherr JL, Tauschmann M, Battelino T, et al. ISPAD clinical practice consensus guidelines 2018: diabetes technologies. Pediatr Diabetes 2018;19:302-25.

4 Benkhadra K, Alahdab F, Tamhane SU, et al. Continuous subcutaneous insulin infusion versus multiple daily injections in individuals with type 1 diabetes: a systematic review and metaanalysis. Endocrine 2017;55:77-84.

5 Misso ML, Egberts KJ, Page M. Continuous subcutaneous insulin infusion (CSII) versus multiple insulin injections for type 1 diabetes mellitus Cochrane database of systematic reviews YR. Cochrane Database Syst Rev 2010:CD005103.

6 Monami M, Lamanna C, Marchionni N, et al. Continuous subcutaneous insulin infusion versus multiple daily insulin injections in type 1 diabetes: a meta-analysis. Acta Diabetol 2010;47:77-81.

7 Pańkowska E, Błazik M, Dziechciarz P, et al. Continuous subcutaneous insulin infusion vs. multiple daily injections in children with type 1 diabetes: a systematic review and meta-analysis of randomized control trials. Pediatr Diabetes 2009;10:52-8.

8 Pickup JC, Sutton AJ. Severe hypoglycaemia and glycaemic control in Type1 diabetes: meta-analysis of multiple daily insulin injections compared with continuous subcutaneous insulin infusion. Diabet Med 2008;25:765-74. 
9 Dos Santos TJ, Donado Campos JdeM, Argente J, et al. Effectiveness and equity of continuous subcutaneous insulin infusions in pediatric type 1 diabetes: a systematic review and meta-analysis of the literature. Diabetes Res Clin Pract 2021;172:108643.

10 van Beers CAJ, DeVries JH. Continuous glucose monitoring: impact on hypoglycemia. J Diabetes Sci Technol 2016;10:1251-8.

11 van Beers CAJ, DeVries JH, Kleijer SJ, et al. Continuous glucose monitoring for patients with type 1 diabetes and impaired awareness of hypoglycaemia (IN CONTROL): a randomised, open-label, crossover trial. Lancet Diabetes Endocrinol 2016;4:893-902.

12 Dovc K, Cargnelutti K, Sturm A, et al. Continuous glucose monitoring use and glucose variability in pre-school children with type 1 diabetes. Diabetes Res Clin Pract 2019;147:76-80.

13 Rubin RR, Peyrot M. Treatment satisfaction and quality of life for an integrated continuous glucose monitoring/insulin pump system compared to self-monitoring plus an insulin pump. J Diabetes Sci Technol 2009;3:1402-10.

14 Calliari LEP, Krakauer M, Gustavo A. Real - world flash glucose monitoring in Brazil : can sensors make a difference in diabetes management in developing countries ? Diabetol Metab Syndr 2020:1-7.

15 Beran $D$. The impact of health systems on diabetes care in low and lower middle income countries. Curr Diab Rep 2015;15:1-13.

16 Addala A, Auzanneau M, Miller K, et al. A decade of disparities in diabetes technology use and $\mathrm{HbA}_{1 \mathrm{c}}$ in pediatric type 1 diabetes: a transatlantic comparison. Diabetes Care 2021;44:133-40.

17 Messer LH, Weinzimer SA. Practical implementation of diabetes technology: real-world use. Diabetes Technol Ther 2020;22:S119-29.

18 Naranjo D, Tanenbaum ML, Iturralde E, et al. Diabetes technology: uptake, outcomes, barriers, and the intersection with distress. J Diabetes Sci Technol 2016;10:852-8.

19 Patton SR, Driscoll KA, Clements MA. Adherence to insulin pump behaviors in young children with type 1 diabetes mellitus : opportunities for intervention. J Diabetes Sci Technol 2017;11:87-91.

20 Tanenbaum ML, Adams RN, Hanes SJ, et al. Optimal use of diabetes devices: clinician perspectives on barriers and adherence to device use. J Diabetes Sci Technol 2017;11:484-92.
21 Messer LH, Tanenbaum ML, Cook PF, et al. Cost, hassle, and onbody experience: barriers to diabetes device use in adolescents and potential intervention targets. Diabetes Technol Ther 2020;22:760-7.

22 American Diabetes Association. Diabetes technology: standards of medical care in diabetes. Diabetes Care 2020;43:S77-88.

23 O'Brien BC, Harris IB, Beckman TJ. Standards for reporting qualitative research: a synthesis of recommendations. Acad Med 2014;89:1245-51.

24 Lavrakas P. Encyclopedia of survey research methods. Vols 1-0. Thousand Oaks, CA: Sage Publications, Inc, 2008.

25 Sherr JL, Hermann JM, Campbell F, et al. Use of insulin pump therapy in children and adolescents with type 1 diabetes and its impact on metabolic control: comparison of results from three large, transatlantic paediatric registries. Diabetologia 2016;59:87-91.

26 Watson SE, Kuhl EA, Foster MB et al. The impact of insurance coverage and the family on pediatric diabetes management. Pediatr Diabetes 2017;18:315-9.

27 Cinek O, Sumník Z, de Beaufort C, et al. Heterogeneity in the systems of pediatric diabetes care across the European Union. Pediatr Diabetes 2012;13:5-14.

28 Sumnik Z, Szypowska A, lotova V, et al. Persistent heterogeneity in diabetes technology reimbursement for children with type 1 diabetes: the SWEET perspective. Pediatr Diabetes 2019;20:434-43.

29 Prahalad P, Addala A, Buckingham BA, et al. Sustained continuous glucose monitor use in low-income youth with type 1 diabetes following insurance coverage supports expansion of continuous glucose monitor coverage for all. Diabetes Technol Ther 2018;20:632-4.

30 Lin MH, Connor CG, Ruedy KJ, et al. Race, socioeconomic status, and treatment center are associated with insulin pump therapy in youth in the first year following diagnosis of type 1 diabetes. Diabetes Technol Ther 2013;15:929-34.

31 Commissariat PV, Boyle CT, Miller KM, et al. Insulin pump use in young children with type 1 diabetes: sociodemographic factors and parent-reported barriers. Diabetes Technol Ther 2017;19:363-9.

32 Hendra R, Hill A. Rethinking response rates: new evidence of little relationship between survey response rates and nonresponse bias. Eval Rev 2019;43:307-30.

33 Watson D. Correcting for Acquiescent response bias in the absence of a balanced scale. Sociol Methods Res 1992;21:52-88. 